\title{
Successful Generation of Hepatitis B virus (HBV) Pseudotype Particle; A Versatile Tool for Identification of the HBV Receptor and Investigation of HBV Infectivity
}

\author{
Keiji Ueda $^{1^{*}}$ and Hiroko Omori ${ }^{2}$ \\ ${ }^{1}$ Department of Microbiology and Immunology, Division of Virology, Osaka University Graduate School of Medicine, 2-2 Yamada-oka, Suita, Osaka 565-0871, Japan \\ 2Institute for Microbial Diseases, Osaka University, 3-1 Yamada-oka, Suita, Osaka 565-0871, Japan
}

"Corresponding author: Keiji Ueda, Division of Virology, Department of Microbiology and Immunology, Osaka University Graduate School of Medicine, 2-2 Yamadaoka, Suita, Osaka 565-0871, Japan, Tel: +81-6-6879-3780; Fax: +81-6-6879-3789; E-mail: kueda@virus.med.osaka-u.ac.jp

Received August 04, 2014; Accepted November 04, 2014; Published November 10, 2014

Copyright: ( 2015 Ueda K, et al. This is an open-access article distributed under the terms of the Creative Commons Attribution License, which permits unrestricted use, distribution, and reproduction in any medium, provided the original author and source are credited.

\begin{abstract}
It is near a half century since hepatitis B virus (HBV) was identified. HBV receptor molecules and the entry mechanism of HBV into hepatocytes have not been elucidated completely, though there are some reports on infection systems and on the receptor molecules. Thus, we still have not reached finding a real HBV receptor and there have been no useful and convenient infection system in vitro and in vivo for HBV, which makes it impossible for us to understand a precise HBV life cycle and HBV involved related diseases. An HBV infection system is really needed to explore ways and means of treatment of HBV related diseases based on evidence as well. Here, we designed and tried to generate an HBV pseudotype, which has a viral particle containing a retrovirus capsid and a genome inside surrounded by HBV membrane proteins. We proved successful generation of this pseudotype by immunoprecipitation with anti-HBVs antibodies and by $\mathrm{CsCl}$ density gradient ultracentrifugation, followed by RT-PCR targeting a retroviral gene, an EGFP gene in this case, respectively. Though our established system is constructed on growth dependent integration of retroviral genomes and thus was very hard to observe its infection in a primary human hepatocytes culture system, successful generation of the HBV pseudotype will make it possible for us to perform a biological assay to clone an HBV receptor based on infectivity and will facilitate its separation and identification.
\end{abstract}

Keywords: HBV; Pseudotype; Infection

\section{Introduction}

It has been near half a century, since hepatitis B virus (HBV) was identified by Blumberg [1]. Though treatment of chronic hepatitis B with interferons has been continued and nucleotide analogs, most of which were explored as anti-HIV agents, and prevention against HBV infection by vaccination has been developed, HBV infected patients yet reach three hundred and fifty million people worldwide [2]. Thus, HBV infection has not been controlled and is one of the biggest viral infections in the world.

There are several animal models, avian hepatitis $B$ viruses such as duck hepatitis B virus (DHBV) and heron hepatitis B virus (HHBV), rodent hepatitis $B$ viruses such as ground squirrel hepatitis virus (GSHV) and woodchuck hepatitis virus (WHV) [2,3]. HBV shows highly species specific spectrum for its infection and can infect only primates and amplify mainly in parenchymal hepatocytes, but never infects the other animals including mice $[2,4]$. Furthermore, even human hepatocyte-originated hepatocellular carcinoma cell lines such as HepG2, HuH7, HuH6, Hep3B and so on never permit HBV infection, or extremely limited even if possible, though there are some reports about in vitro infection of HBV to HepG2 $[5,6]$.

As HBV infection systems, human normal hepatocytes and a human hepatocellular carcinoma originated cell line have been available on the commercial base $[7,8]$ and uPA/SCID mice with human hepatocytes have been developed [9-11]. These systems are very useful for $\mathrm{HBV}$ and hepatitis $\mathrm{C}$ virus $(\mathrm{HCV})$ research indeed but they are very expensive and inconvenient for daily HBV research. Thus, there is still a high hurdle to expand knowledge about HBV.

Actually, many studies about HBV and its related diseases such as acute and chronic hepatitis, cirrhosis and hepatocellular carcinoma have been performed so far [12-15]. Such studies, however, were very limited because of absence of a useful and convenient in vitro infection system for $\mathrm{HBV}$ as mentioned. In order to overcome such a big problem, we need very useful, convenient and inexpensive systems for HBV infection to understand a true HBV life cycle and pathogenesis of $\mathrm{HBV}$ related diseases, and then to develop specific drugs and means to treat such diseases.

Identification of an $\mathrm{HBV}$ receptor is indispensable to establish in vitro and in vivo or a convenient animal infection model. Information on the HBV receptor has been reported, including non-human hepadnaviruses such as duck hepatitis B virus [16-18] and such seems not to be a real and complete HBV receptor, and has not reached establishing an HBV infection system in culture system. HBV can infect primary hepatocytes for sure whose preparation is still troublesome, and although there are several human hepatocytes originated hepatocellular carcinoma cell lines as noted, we do not know why such cell lines becomes insusceptible to HBV infection, which might mean that differentiation status of hepatocyte could be critical for the expression and/or the activity of an $\mathrm{HBV}$ receptor $[19,20]$.

It should be very difficult to identify an HBV receptor and thus we must design a revolutionary method for the identification. Pseudotype 
viruses could be very useful not only to transfer and express some genes exogenously but also to monitor their infectivity [21]. VSV-G based pseudotype containing retroviral vectors and lentiviral VSV-G pseudotype vectors have been proved to be extremely useful to transduce heterologous genes into cells and in case of the latter, even into resting cells such as well-differentiated neuronal cells [22-24]. On the other hand, specific viral enveloped pseudotype viruses could be helpful to test what kinds of cells and how such viruses can infect. Though HCV pseudotype particles (HCVpp), in which lentiviral capsids are enveloped by HCV membrane proteins, has been successfully generated and utilized without any knowledge of viral particle maturation and egress [25]. Thus, the bottleneck is dependent on whether such pseudotype particles really can be generated or not.

Here, we challenged to develop HBV pseudotype particles (HBVpp), which consist of HBV membrane particles outside and murine leukemia virus (MLV) originated capsids and genomes insides. Therein, we prepared a packaging cell system, where the cells produce MLV gag-pol fusion polypeptides and a retroviral genome containing an EGFP gene and a hygromycin resistant gene (hygR) in addition to murine leukemia virus packaging signal $\psi$. Pantropic retroviruses with vesicular stomatitis virus $G$ proteins were successfully generated in our generated packaging system and infected the other cell lines, meaning that the packaging cell lines were practicable. Introducing an HBV membrane protein expression vector into the packaging cells, which expresses three HBV membrane proteins, large S (LS), middle S (MS) and small $S$ (SS) enabled release of particles enveloped by HBV membrane proteins. Immunoprecipitation with anti-S antibodies followed by RNA extraction and reverse transcription-polymerase chain reaction (RT-PCR) targeted the EGFP gene revealed the designed retroviral genome inside. Physico-chemical studies using CsCl-density gradient ultracentrifugation followed by RNA extraction and RT-PCR targeted the EGFP gene also revealed that the particles focused around $1.22 \sim 1.25 \mathrm{~g} / \mathrm{ml}$ density zone, which was consistent with the HBV particle density, and the retroviral genomes were inside.

Successful formation of an HBVpp seems to be very useful and practical for identification of an HBV receptor since we are able to establish an assay system based on the viral infectivity by using versatile cell culture systems, though our system is an MLV based packaging system, which depends on cell growth for their integration.

\section{Materials and Methods}

\section{Cells}

HEK293, a human embryonic kidney cell line, and its derivatives, GP2-293 (Clontech-Takara Bio), in which an MMLV gag-pol gene was stably integrated for its expression, were maintained in Dulbecco's modified essential medium (DMEM) (nakalai tesquec) supplemented with $10 \mathrm{IU} / \mathrm{ml}$ penicillin $\mathrm{G}, 10 \mu \mathrm{g} / \mathrm{ml}$ streptomycin and $10 \%$ fetal bovine serum (FBS), and BC3, a human primary effusion lymphoma cell line in RPMI1640 (nakalai tesque) supplemented with the same antibiotics and $20 \%$ fetal bovine serum [5]. All cells were cultured in $5 \%$ CO2 atmosphere. For the selection, hygromycin B (Wako Chemicals Japan) was added into each medium at $0.5 \mathrm{mg} / \mathrm{ml}$.

\section{Plasmids}

A retroviral expression vector, pHyTc-GFP was consisted of 5' and 3' LTR, a $\psi$ packaging signal, a hygromycin resistant gene (hygR) at the gag-pol position, the cytomegalovirus (CMV) enhancer-promoter region followed by an EGFP gene from pEGFP C1 (Clontech) at the env position (Figure $1 \mathrm{~A}$ ). pCEP4 LS-S was an HBV membrane protein expression vector and contained BstEII to EcoRV fragment of the cloned HBV DNA subtype adw2 (Accession No. X02763.1, GI: 59418) at a PvuII site of pCEP4 vector (Invitrogen).

\section{Transfection and establishment of packaging cell lines}

pHyTc-GFP was transfected to GP2-293 cells (Clontech-Takara Bio) with a transfection reagent, TransIT LT1 (Takara Bio) according to manufacturer's direction. Two days after transfection, the cells were selected in $0.5 \mathrm{mg} / \mathrm{ml}$ hygromycin B (Wako Chemicals, Japan) containing DMEM with supplements mentioned above. Several colonies with GFP-positive signals were isolated with a penicillin ring and propagated. To check their packaging activity, a VSV-G expression vector (Clontech) was transfected to the isolated clones and the culture medium was harvested three days post-transfection. The medium was passed through a $0.22 \mu \mathrm{m}$ filter unit (Millex, Millipore) and stored at $4^{\circ} \mathrm{C}$ until use. $2 \times 105$ BC 3 cells or HEK293 were prepared in a 6 -well plate and the virus containing medium was contacted with them for 4 hours. The medium was withdrawn and incubated for two days in the DMEM for HEK293 and RPMI1640 for BC3 supplemented with antibiotics and FBS as mentioned above. Then, the medium changed to hygromycin B containing one as above and GFP-positive colonies were counted and the best clone was maintained for further experiment. The established packaging cell lines were termed gfp/GP2.

To generate HBV pseudotype particles (HBVpp), the established packaging cell line, gfp/GP2 was transfected with the pCEP4 LS-S expression vector with TransIT LT1 (Takara Bio) as mentioned. Two days after transfection, the supernatant was harvested and passed through a $0.22 \mu \mathrm{m}$ filter as mentioned.

\section{Immunoprecipitation and western blotting analysis}

Supernatant from pCEP4 LS-S transfected gfp/293GP2 cells was adjusted at $0.3 \mathrm{M} \mathrm{NaCl}$ and incubated with goat polyclonal anti-HBs antibodies (Austral Biologicals) at $4^{\circ} \mathrm{C}$ overnight. Then the supernatant was added $20 \mu \mathrm{l}$ protein G Sepharose ${ }^{\otimes}$ (GE Healthcare) and incubated for $20 \mathrm{~min}$ at RT. The complex was pelleted and washed with sodium phosphate buffer (50 mM Na-phosphate $\mathrm{pH}$ 7.8, $0.3 \mathrm{M}$ $\mathrm{NaCl}$ ) three times. Finally, half of the pellet was suspended in sample buffer (5 mM 2-mercaptoethanol, 5\% SDS, 0.3\% bromophenol blue, $10 \%$ glycerol) and an aliquot was subjected to SDS-PAGE followed by Western blotting analysis using a mouse monoclonal antibody against HBsAg (HBs mAb \#7-2).

$\mathrm{CsCl}$ density gradient ultracentrifugation and Enzyme-linked immunosorbent assay (ELISA) for HBs and preS1.

The culture medium of pCEP4 LS-S transfeted gfp/GP2 cells was harvested as above and was added $30 \%$ polyethyleneglycol (PEG6000, nakalai tesque) $-3 \mathrm{M} \mathrm{NaCl}$ at $5 \%$ PEG and $0.5 \mathrm{M} \mathrm{NaCl}$ of final concentration. This solution was stood at $4^{\circ} \mathrm{C}$ more than half an hour and then centrifuged at $10,000 \times \mathrm{g}$ for $30 \mathrm{~min}$ at $4^{\circ} \mathrm{C}$. The precipitate was suspended in $500 \mu 10 \mathrm{mM}$ Tris- $\mathrm{HCl}, \mathrm{pH}$ 7.6-100 mM NaCl-1 mM EDTA (TNE) solution and clarified insoluble materials. The soluble fraction was loaded at the top of $\mathrm{CsCl}$ gradient solution $(39 \mathrm{~F}$ $350 \mu \mathrm{l}, 35 \mathrm{~F} 2500 \mu \mathrm{l}, 31 \mathrm{~F} 250 \mu \mathrm{l}$, 27F $250 \mu \mathrm{l}$, 23F $250 \mu \mathrm{l}$, 19F $250 \mu \mathrm{l}$ and $15 \mathrm{~F} 150 \mu \mathrm{l}$ from the bottom, $\mathrm{F}$; $\mathrm{CsCl}$ percentage in weight) and centrifuged at $50,000 \mathrm{rpm}$ at $10^{\circ} \mathrm{C}$ for 30 hours using a Beckman Ti55 rotor and Optima ${ }^{\oplus}$ TLX ultracentrifuge (Beckman). After the centrifugation, eighteen fractions were taken from the top by the 120 
$\mu$ l. An aliquot (about $10 \mu \mathrm{l}$ ) from each fraction was diluted with $90 \mu \mathrm{l}$ PBS and subjected to ELISA using HBs Antigen (HBsAg) Quantitative ELISA Kit Rapid $\mathrm{II}^{\oplus}$ for HBs and HBV PreS1 Antigen Quatitative $\mathrm{Kit}^{\oplus}$ (Beakle Inc., Japan) for preS1, respectively, according to the manufacturer's direction. Forty microliter of the aliquot was subjected to RNA extraction followed by RT-PCR targeting an EGFP gene.

\section{Detection of a retrovirus gene in the particle by RT-PCR}

The supernatant from pCEP4 LS-S transfected gfp/GP2 cells was adjusted at $0.3 \mathrm{M} \mathrm{NaCl}$ was incubated either with goat polyclonal antiHBs antibodies $(1 \mu \mathrm{g} / \mathrm{ml}$ ) (Austral Biologicals) or rabbit anti-VSV-G antibodies $(1 \mu \mathrm{g} / \mathrm{ml})(\mathrm{MBL})$ at $4^{\circ} \mathrm{C}$ overnight. This mixture then incubated with $20 \mu \mathrm{l}$ protein-G Sepharose ${ }^{\oplus}$ (GE Healthcare) for $20 \mathrm{~min}$ at RT. The complex was pelleted and washed with sodium phosphate buffer (50 mM Na-phosphate $\mathrm{pH} 7.8,0.3 \mathrm{M} \mathrm{NaCl}$ ) three times. The final pellet and $40 \mu \mathrm{l}$ from each fraction of $\mathrm{CsCl}$ density gradient ultracentrifugation as mentioned above was added $200 \mu \mathrm{l}$ or $160 \mu \mathrm{l}$ TNE, respectively, and $2 \mu \mathrm{l} 10 \%$ SDS and incubated with $20 \mu \mathrm{g}$ Protainase K (Roche) at $56{ }^{\circ} \mathrm{C}$ overnight, respectively. The solution was extracted with phenol-chloroform-isoamylalcohol (24:24:1) and precipitated with ethanol with $10 \mu \mathrm{g}$ yeast tRNA by centrifugation at $10,000 \times \mathrm{g}$ at $4^{\circ} \mathrm{C}$ for $10 \mathrm{~min}$. The precipitate was rinsed with $70 \%$ ethanol and dried and suspended $20 \mu \mathrm{TE}(10 \mathrm{mM}$ Tris- $\mathrm{HCl} \mathrm{pH}$ 7.6, 1 mM EDTA).

$5 \mu \mathrm{l}$ of the preparation was subjected to reverse transcription reaction by using first strand synthesis kit (Transcriptor First Stand cDNA Synthesis $\mathrm{Kit}^{\oplus}$, Roche) according to the manufacturer's direction. This reaction was stopped with phenol-chloroformisoamylalcohol (24:24:1) extraction followed by ethanol precipitation with $10 \mu \mathrm{g}$ yeast tRNA as mentioned above. Finally, the dried pellet was suspended in $20 \mu \mathrm{l}$ TE. Either $5 \mu \mathrm{l}$ out of $20 \mu \mathrm{l}$ cDNA sample or 5 $\mu \mathrm{l}$ of RNA preparation sample was constituted in PCR using an EGFP 5' primer; 5'-ACGGCAACATCCTGGGGCACAAGC-3', and an EGFP 1327RV primer; 5'-TGTACAGCTCGTCCATGCCGAGAG-3' and $\mathrm{Ex} \mathrm{Taq}^{\circ} \mathrm{DNA}$ polymerase (Takara Bio) according to the manufacturer's direction. The PCR condition was $96^{\circ} \mathrm{C}$ for $30 \mathrm{sec}$, $54^{\circ} \mathrm{C}$ for $30 \mathrm{sec}$, and $72^{\circ} \mathrm{C}$ for $1 \mathrm{~min}$ with 35 cycles. One fourth of the reaction $(5 \mu \mathrm{l})$ was run in the $2 \%$ agarose gel electrophoresis stained with ethidium bromide. A digital image of the DNA was obtained using a fluorescent imager (FX-800 ${ }^{\circ}$, BioRad).

\section{Electron microscopy}

Cells were cultured on a polystyrene cover slip, Cell Desk (Sumitomo Bakelite Co., Ltd., Japan), fixed with $2 \%$ formaldehyde and $2.5 \%$ glutaraldehyde in $0.1 \mathrm{M}$ sodium-acodylate buffer ( $\mathrm{pH} 7.4$ ) and washed for $5 \mathrm{~min}$ three times in the same buffer. Cells were post-fixed for $1 \mathrm{hr}$ with $1 \%$ osmium tetroxide and $0.5 \%$ potassium ferrocyanide in $0.1 \mathrm{M}$ sodium-cacodylate buffer ( $\mathrm{pH} 7.4$ ), dehydrated in graded series of ethanol and embedded in Epon $812^{\circ}$ (TAAB Co. Ltd., UK). 80 $\mathrm{nm}$ ultra-thin sections were stained with saturated uranyl acetate and lead citrate solution. Electron micrographs were obtained with a JEM- $1011^{\circ}$ transmission electron microscope (JEOL, Japan).

\section{Results}

\section{Establishment of HBV psuedotype packaging cells}

We utilized a murine leukemia virus (MLV) packaging system since considering in vitro use for biological cloning of an $\mathrm{HBV}$ receptor in cultured cell lines based on infectivity and for checking infectivity of HBV with ease afterwards, even though mature hepatocytes have a limited growth activity in vitro. Retroviral genomes are integrated into host genome after reverse-transcribed only in growing cells except those of lentiviruses, which were utilized in a previous report [24]. Thus, the packaging design was a commonly used retrovirus packaging system consisting of 5 '-LTR-packaging signal ( $\Psi$ )-hygRCMV IE promoter-GFP-LTR-3' (Figure 1A). This construct was integrated into a retrovirus gag-pol expressing GP2-293 cell line (Clontech), the cell line of which was termed gfp/GP2 (Figure 1B). Thus, the transcribed RNA genome was packaged into MLV capsids. We attempted that upon envelope expression and processing, the capsids would be incorporated into enveloped particles and secreted. If HBV membrane proteins could envelope the retroviral capsid, HBV pseudotype particles (HBVpp) would be formed (Figure 1C).

A

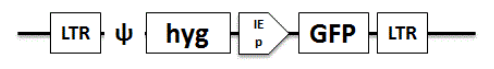

B

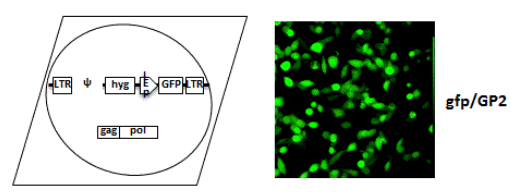

C

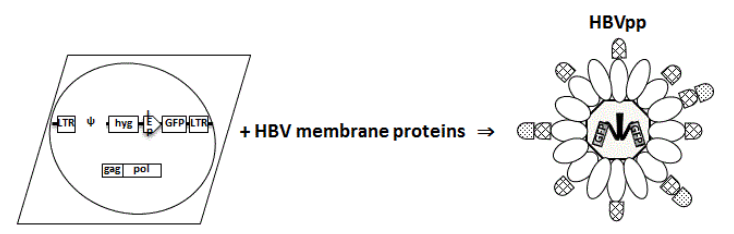

Figure 1: Design of HBVpp packaging system. A. Construct of the retroviral genome. A MLV-based retroviral vector was constructed. As commonly used, this vector was two LTRs at the 5' and the $3^{\prime}$ end. A Packaging signal $(\Psi)$, a selection marker (HygR), a CMV immediate early enhancer and promoter followed by a GFP gene are represented. B. An established packaging cell line is shown. This cells was generated in MLV gag-pol expressing GP2 (Clontech) cells, where the retroviral vector (see Figure 1A) was integrated. As a result, the packaging cells express the HygR and the GFP in addition to MLV gag-pol. C. A strategy of the generation of HBVpp. The established packaging cells could produce HBV membrane protein enveloped retroviral capsids, when HBV membrane proteins were successfully expressed.

In order to confirm whether the established packaging cell lines were available or not, we transfected to the cells with a VSV-G expression vector (Takara Bio Clontech) to form a VSV-G pseudotype (in case, this pseudotype is called a pantropic retrovirus) and its infectivity. If the packaging cell lines were available, so-called pseudotype retroviruses wrapped by VSV-G envelope would be generated and secreted into the culture medium. Thus, the supernatant of the VSV-G expressing packaging cells was contacted with $\mathrm{BC} 3$, a primary effusion lymphoma cell line or with the other cell lines. Two days after the contact, the infected BC3 cells were selected with a hygromycin $\mathrm{B}$ containing medium and we observed that 
hygromycin B resistant cells were growing and such cells showed GFP positive signals (Data not shown). Several cell lines including HeG2, HuH7, and HEK293 cells were effectively infected with the VSV-G pseudotype retrovirus. These results showed that the packaging system was functional and termed gfp/GP2.

\section{Expression of HBV envelope genes}

There are three envelope genes termed large S (LS), middle S (MS) and small S (SS, also called simply HBs) (Figure 2A) [2,26]. Each gene is independently transcribed but the coding regions are overlapped. We constructed an HBV membrane protein expression vector termed pCEP4 LS-S under CMV immediate early enhancer and promoter (CMV IEp) in the pCEP4 expression vector (Invitrogen) (Figure 2B). We were afraid that such strong enhancer and promoter just upstream the LS gene preferentially might drive mainly the LS gene expression, because a balance among HBV envelope proteins affected secretion activity of the virus particles [27]. Transfected cells with the pCEP4 LS-S, however, expressed generally all kinds of HBV envelope genes as reported (Figure 2C) [28].
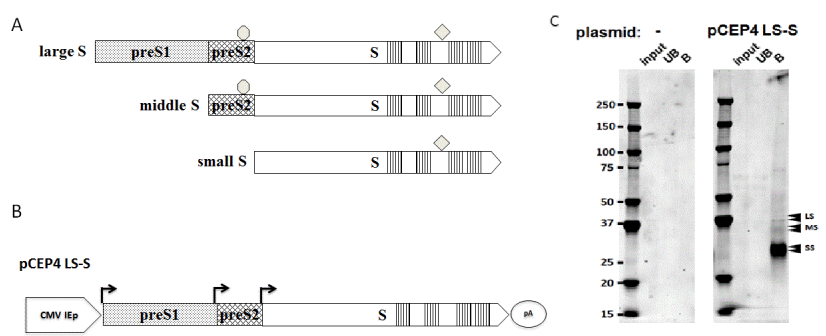

Figure 2: HBV membrane proteins and their expressing plasmid, pCEP4 LS-S. A. Three HBV membrane proteins are shown. The S region is shared by all $\mathrm{HBV}$ membrane proteins. A hexagon and a diamond represent an $\mathrm{O}$-glycosylation and an $\mathrm{N}$-glycosylation site, respectively. B. An expression map of HBV membrane proteins. Arrows represent putative transcription start sites for each $\mathrm{HBV}$ membrane gene. C. HBV membrane protein expression was analyzed by immunoprecipitation with rabbit polyclonal anti-HBs antibodies followed by Western blot with a mouse monoclonal anti-HBs antibody. Input: lysate from the transfected cells. UB: unbound fractions with goat polyclonal anti-HBs antibodies (Austral Biologicals). B: bound fractions with the same antibodies. Arrowheads show authentic HBV membrane proteins.

\section{Formation and secretion of $\mathrm{HBV}$ pseudotype particles into medium}

Next question was whether our designed HBVpp would be formed and secreted into medium from the packaging cells transfected with the HBV envelopes expression vector (pCEP4 LS-S). Immunoprecipitates with anti-HBs antibodies from the supernatant of pCEP4 LS-S transfected and non-transfected gfp/GP2 cells were analyzed by Western blotting analysis to detect HBV envelope proteins. Figure $2 \mathrm{C}$ showed that all $\mathrm{HBV}$ envelopes were expressed and actually LS, MS and SS protein expression were detected. Thus, expressed HBV envelope proteins were secreted into medium.

\section{Secreted envelope proteins contains the designed retroviral genome}

In order to check whether HBV membrane proteins can envelope retroviral capsids, culture medium of pCEP4 LS-S transfected gfp/GP2 cells was harvested and immunoprecipitated either with anti-HBs antibodies or anti-VSV-G antibodies in case that VSV-G was expressed. Reverse transcription (RT) was performed on the RNA extracted from the immunoprecipitates. VSV-G pseudotype was also tested as a positive control. As shown in Figure 3, a correct size of amplified band was observed in LS-S expressed samples as in VSV-G. This result (about $\sim 320 \mathrm{bp}$ ) suggests that HBV envelope proteins wrapped retroviral capsids containing retroviral genomes, in which GFP and hygR genes were encoded in this case.

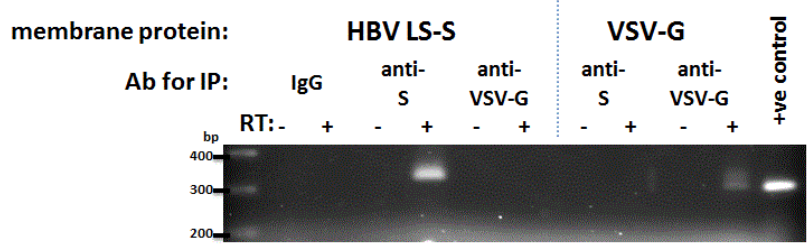

Figure 3: HBV membrane bound particles contains retroviral genomes inside. A. Culture medium of either HBV LS-S or VSV-G transfected packaging cells was immunoprecipitated with anti-S antibodies or anti-VSV-G antibodies. Putative RNA genomes were extracted from the immunoprecipitates and subjected to RT-PCR for the EGFP gene. Ab: antibody, IP: immunoprecipitation, RT: reverse transcription, +ve: positive.

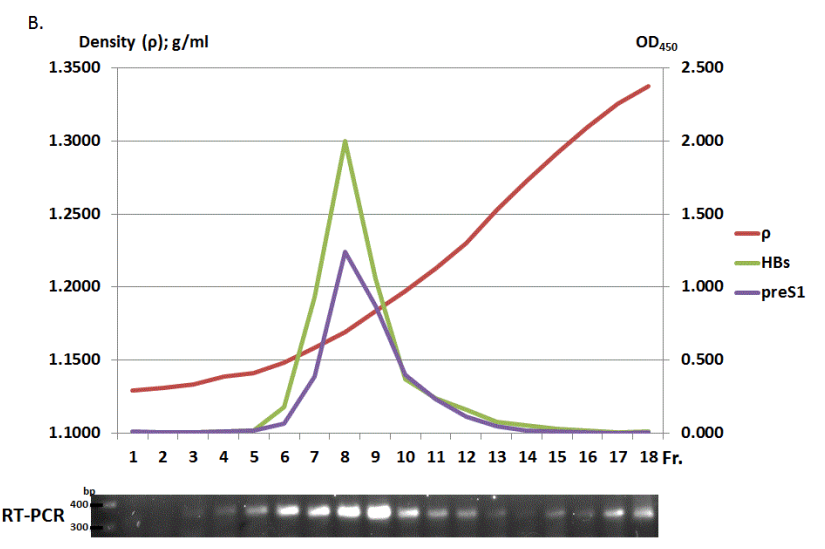

Figure 3B: $\mathrm{CsCl}$ density gradient ultracentrifugaion profile, ELISA and RT-PCR of the each fraction. (Upper) Profiles of the density, ELISA for HBV membrane proteins (HBs and preS1). The left longitudinal axis shows the density of each fraction. $\rho$ : density, $\mathrm{mg} / \mathrm{ml}$. The right longitudinal axis shows OD450 values for HBs and preS1 measured with ELISA kits. (Lower) An agarose-gel electrophoresis of RT-PCR products of the EGFP gene as a target (about 320 bp). 
HBVpp shows near identical density profiles to $\mathrm{HBV}$ particles (Dane particles) in $\mathrm{CsCl}$ density gradient ultracentrifugation.

Next, we checked the density profiles of HBVp particles in $\mathrm{CsCl}$ density gradient untracentrifugation. Peak fractions for HBs and preS1 were seen in fraction 8 whose density was around $1.17 \mathrm{~g} / \mathrm{ml}$. Furthermore, amplified EGFP-corresponding DNA by RT-PCR was detected around the fractions positive for HBsAg. The main RT-PCR products were detected in fraction 9 with higher density $(1.18 \mathrm{~g} / \mathrm{ml})$ than those where the most $\mathrm{S}$ and preS1 antigens were detected (fraction 8). The produced pseudotyped HBV particles were a little bit smaller than the native HBV, since it was reported that Dane particles had the heavier density (around $1.25 \mathrm{~g} / \mathrm{ml}$ ) than small $\mathrm{S}$ particles $(1.20 \sim 1.22 \mathrm{~g} / \mathrm{ml})$ [29]. Taken together, these observations suggest that retroviral capsids surrounded by $\mathrm{HBV}$ membrane proteins were generated and secreted into the medium from the packaging cells expressing HBV membranes and thus the HBV pp was produced.

\section{Observation of HBVpp by electron microscopy}

Finally, we tried to observe HBVpp from the packaging cells transfected HBV membrane protein expression vectors by electron microscopy. Unfortunately, we were not able to observe the complete particles on the secretion process but viral-like-particles in the endoplasmic reticulum of the packaging cells expressing HBV membrane proteins (Figure 4A). Most of them might be subviral particles ie., HBs particles. We also observed some typical Dane-like particles in the medium (Figure $4 \mathrm{~B}$ ), though infectious viral particle formation might not be efficient with this method.
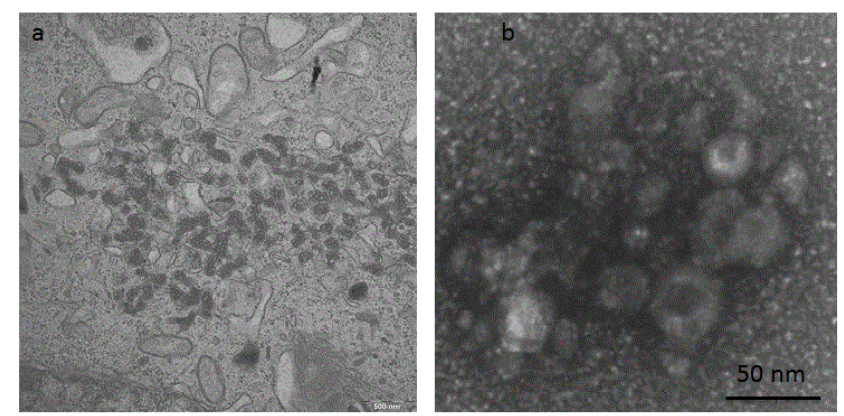

Figure 4: Electronmicroscopy of intracellular sub-viral particles and secreted virus-like particles. a. Sub-viral particles accumulation was seen in the ER of LS-S expressing packaging cells. b. Secreted viruslike particles are shown.

\section{Discussion}

$\mathrm{HBV}$ is a small DNA virus with $3.2 \mathrm{~kb}$ genome involved in acute and chronic liver diseases, persistence of which is predisposed to in a sense incurable liver cirrhosis and cancer. It is assumed that there are more than a few hundred million infected people and thus this is one of the biggest infectious diseases in the world [2]. Since vaccine was developed, protection from the virus infection has been enabled except some vaccine escape mutants [30,31]. And it is certain that several nucleotide analogs effectively inhibit the viral replication and then disease progression $[32,33]$. Nevertheless, the real virus life cycle has remained to be elucidated. The critical reason why there are a lot of mysteries about $\mathrm{HBV}$ is mainly due to no convenient in vitro and/or in vivo infection system for $\mathrm{HBV}$, though there are several animal hepadnavirus models such avian (duck and heron) and rodent (ground tree squirrel and woodchuck) hepatitis B viruses. Hatching and raising such animals and preparation of primary cultured hepatocytes from the liver of them are not so easy for daily research activities and animal hepadnaviruses are quite divergent and unlikely to be good models for HBV.

Recent progress of tissue culture system from a hepatocellular carcinoma called HepaRG $[7,34]$ and from primary hepatocytes of Tupaia belangeri $[35,36]$ enable us to propagate $\mathrm{HBV}$ in in vitro infection system to some extent. By differentiation of the cells to differentiated parenchymal hepatocytes with $2 \%$ DMSO as well as hydrocortisone, HBV can infect the HepaRG up to $20 \%$ or so at viral genome equivalent (V.G.E.) to a cell of over $200[7,34,37]$. The infected $\mathrm{HBV}$, however, did not produce infectious daughter viruses in spite of observation of Dane-like particle formation [34]. Furthermore, it takes more than two weeks to differentiate the HepaRG to susceptible for HBV infection [7]. Thus, HepaRG cells are useful but it would be still less efficient for HBV infection and time-consuming system to analyze the HBV life cycle.

It is reasonable to find out an HBV receptor in order to overcome this situation followed by establishing a HBV infection system. Several candidates for HBV receptors have been reported. Starting from polymerized human serum albumin, several kinds of molecules; endonexin II, asialoglycoprotein receptor (ASGPR), lipoprotein lipase (LPL), gp120 and gp180 (carboxypeptidase D) and so on were reported for HBV receptors, including those for DHBV [17,38-44]. None of them, however, has been utilized for establishing an in vitro $\mathrm{HBV}$ infection system as an $\mathrm{HBV}$ receptor molecule. And most recently, NTCP (sodium-taurocholate co-transporting protein) has been nominated as a plausible HBV receptor molecule, which has been under evaluation [45-47].

On the other hand, the ligand, i.e., HBV membrane proteins have been characterized as well. There are three kinds of HBV membrane proteins; large S (LS), middle S (MS) and small S (SS) and seems to be no doubt that preS1 region in the N-terminal end of LS has a key role for receptor binding [48]. Especially, a well-conserved region around preS1 9-23 amino acids (aa) might be critically important and might function as a fusogenic peptide, since antibodies against preS1 (2-48 aa) could neutralize HBV infection but not preS1 (1-21 aa) in PTH system [49-51]. And also, experiments using hepatitis delta virus (HDV) provided us with similar important information on the HBV entry [52-54].

Nevertheless, we have yet obtained an easy and convenient in vitro cell culture system for HBV infection. Thus, identifying an HBV receptor seems to be very hard, because it has not been achieved for a half century since HBV was found. We do not understand why classical methods such as a phage screening system expressing human liver cDNA library and so on do not work well and therefore, we may need to design a new revolutionary assay system.

We here would like to propose a new biological assay using HBV pseudotype particles (HBVpp) in which retroviral core particles were enveloped by HBV membrane proteins. Successful production of HBVpp would allow us to test HBVpp infectivity to cell culture systems introduced some cDNA library from human hepatocytes and/or differentiated HepaRG cells. In this report, we tested whether such HBVpp could be generated. The immunoprecipitation with antiHBs antibodies followed by RT-PCR and the physicochemical study 
using ultracentrifugation followed by RT-PCR revealed that murine leukemia virus based core/capsid, which contained recombinant retroviral genomes with EGFP and HygR, were enveloped by HBV membrane particles. Thus, HBVpp should be generated and next question would be whether this HBVpp really could infect welldifferentiated hepatocytes at suitable condition. It could be a weak point that the HBVpp was based on murine leukemia virus, which demanded cell growth for efficient viral genome integration into the host genome, compared to the same kind system based on a lentivirus. The HBV receptor could be a complex consisted of several molecules. In such a case, it should be very difficult to clone the HBV receptor by cDNA library introduction to ordinary cells, since two hits or more might be required. Nevertheless, it could possibly work if a cDNA encoding an HBV receptor or a gene affecting HBV attachment and entry from a human liver source was tested for HBV infectivity in various hepatoma cell culture systems and thus this HBVpp will be a powerful tool for separation and identification of an HBV receptor with infectivity as a polestar.

\section{References}

1. Blumberg BS, Alter HJ, Visnich S (1965) A "New" Antigen in Leukemia Sera. JAMA 191: 541-546.

2. Seeger C, Zoulim F, Mason WS (2007) Hepadnaviruses, Lippincott Williams and Wilkins, Philadelphia.

3. Funk A, Mhamdi M, Will H, Sirma H (2007) Avian hepatitis B viruses: molecular and cellular biology, phylogenesis, and host tropism. World J Gastroenterol 13: 91-103.

4. Sureau C, Eichberg JW, Hubbard GB, Romet-Lemonne JL, Essex M (1988) A molecularly cloned hepatitis B virus produced in vitro is infectious in a chimpanzee. J Virol 62: 3064-3067.

5. Bchini R, Capel F, Dauguet C, Dubanchet S, Petit MA (1990) In vitro infection of human hepatoma (HepG2) cells with hepatitis B virus. J Virol 64: 3025-3032.

6. Paran N, Geiger B, Shaul Y (2001) HBV infection of cell culture: evidence for multivalent and cooperative attachment. EMBO J 20: 4443-4453.

7. Gripon P, Rumin S, Urban S, Le Seyec J, Glaise D, et al. (2002) Infection of a human hepatoma cell line by hepatitis B virus. Proc Natl Acad Sci U S A 99: 15655-15660.

8. Marion MJ, Hantz O, Durantel D (2010) The HepaRG cell line: biological properties and relevance as a tool for cell biology, drug metabolism, and virology studies. Methods Mol Biol 640: 261-272.

9. Bissig KD, Wieland SF, Tran P, Isogawa M, Le TT, et al. (2010) Human liver chimeric mice provide a model for hepatitis $\mathrm{B}$ and $\mathrm{C}$ virus infection and treatment. J Clin Invest 120: 924-930.

10. Meuleman P, Leroux-Roels G (2008) The human liver-uPA-SCID mouse: a model for the evaluation of antiviral compounds against HBV and HCV. Antiviral Res 80: 231-238.

11. Dandri M, Burda MR, Török E, Pollok JM, Iwanska A, et al. (2001) Repopulation of mouse liver with human hepatocytes and in vivo infection with hepatitis B virus. Hepatology 33: 981-988.

12. Llovet JM, Burroughs A, Bruix J (2003) Hepatocellular carcinoma. Lancet 362: 1907-1917.

13. Kremsdorf D, Soussan P, Paterlini-Brechot P, Brechot C (2006) Hepatitis $B$ virus-related hepatocellular carcinoma: paradigms for viral-related human carcinogenesis. Oncogene 25: 3823-3833.

14. Lupberger J, Hildt E (2007) Hepatitis B virus-induced oncogenesis. World J Gastroenterol 13: 74-81.

15. Baumert TF, Thimme R, von Weizsäcker F (2007) Pathogenesis of hepatitis B virus infection. World J Gastroenterol 13: 82-90.

16. Li JS, Tong SP, Wands JR (1996) Characterization of a 120-Kilodalton pre-S-binding protein as a candidate duck hepatitis B virus receptor. J Virol 70: 6029-6035.
17. Kuroki K, Cheung R, Marion PL, Ganem D (1994) A cell surface protein that binds avian hepatitis B virus particles. J Virol 68: 2091-2096.

18. Breiner KM, Urban S, Schaller H (1998) Carboxypeptidase D (gp180), a Golgi-resident protein, functions in the attachment and entry of avian hepatitis B viruses. J Virol 72: 8098-8104.

19. Cerec V, Glaise D, Garnier D, Morosan S, Turlin B, et al. (2007) Transdifferentiation of hepatocyte-like cells from the human hepatoma HepaRG cell line through bipotent progenitor. Hepatology 45: 957-967.

20. Parent R, Marion MJ, Furio L, Trépo C, Petit MA (2004) Origin and characterization of a human bipotent liver progenitor cell line. Gastroenterology 126: 1147-1156.

21. . (2011) Lentiviral vectors: their molecular design, safety, and use in laboratory and preclinical research. Hum Gene Ther 22: 649-657.

22. Sung VM, Lai MM (2002) Murine retroviral pseudotype virus containing hepatitis B virus large and small surface antigens confers specific tropism for primary human hepatocytes: a potential liver-specific targeting system. J Virol 76: 912-917.

23. Saha MN, Tanaka A, Jinno-Oue A, Shimizu N, Tamura K, et al. (2005) Formation of vesicular stomatitis virus pseudotypes bearing surface proteins of hepatitis B virus. J Virol 79: 12566-12574.

24. Chai N, Chang HE, Nicolas E, Gudima S, Chang J, et al. (2007) Assembly of hepatitis $\mathrm{B}$ virus envelope proteins onto a lentivirus pseudotype that infects primary human hepatocytes. J Virol 81: 10897-10904.

25. Evans MJ, von Hahn T, Tscherne DM, Syder AJ, Panis M, et al. (2007) Claudin-1 is a hepatitis $\mathrm{C}$ virus co-receptor required for a late step in entry. Nature 446: 801-805.

26. Glebe D, Urban S (2007) Viral and cellular determinants involved in hepadnaviral entry. World J Gastroenterol 13: 22-38.

27. Ueda K, Tsurimoto T, Matsubara K (1991) Three envelope proteins of hepatitis B virus: large $S$, middle $S$, and major $S$ proteins needed for the formation of Dane particles. J Virol 65: 3521-3529.

28. Bruss V, Ganem D (1991) The role of envelope proteins in hepatitis B virus assembly. Proc Natl Acad Sci U S A 88: 1059-1063.

29. Chairez R, Hollinger FB, Melnick JL, Dreesman GR (1974) Biophysical properties of purified morphologic forms of hepatitis B antigen. Intervirology 3: 129-140.

30. Lacombe K, Boyd A, Gozlan J, Lavocat F, Girard PM, et al. (2010) Drugresistant and immune-escape HBV mutants in HIV-infected hosts. Antivir Ther 15: 493-497.

31. Sheldon J, Soriano V (2008) Hepatitis B virus escape mutants induced by antiviral therapy. J Antimicrob Chemother 61: 766-768

32. Zoulim F (2006) Antiviral therapy of chronic hepatitis B. Antiviral Res 71: 206-215.

33. Locarnini SA, Yuen L (2010) Molecular genesis of drug-resistant and vaccine-escape HBV mutants. Antivir Ther 15: 451-461.

34. Gripon P, Diot C, Guguen-Guillouzo C (1993) Reproducible high level infection of cultured adult human hepatocytes by hepatitis B virus: effect of polyethylene glycol on adsorption and penetration. Virology 192: 534-540.

35. Köck J, Nassal M, MacNelly S, Baumert TF, Blum HE, et al. (2001) Efficient infection of primary tupaia hepatocytes with purified human and woolly monkey hepatitis B virus. J Virol 75: 5084-5089.

36. Lanford RE, Chavez D, Brasky KM, Burns RB 3rd, Rico-Hesse R (1998) Isolation of a hepadnavirus from the woolly monkey, a New World primate. Proc Natl Acad Sci U S A 95: 5757-5761.

37. Hantz O, Parent R, Durantel D, Gripon P, Guguen-Guillouzo C, et al. (2009) Persistence of the hepatitis B virus covalently closed circular DNA in HepaRG human hepatocyte-like cells. J Gen Virol 90: 127-135.

38. Yu MW, Finlayson JS, Shih JW (1985) Interaction between various polymerized human albumins and hepatitis B surface antigen. J Virol 55: 736-743.

39. Pontisso P, Petit MA, Bankowski MJ, Peeples ME (1989) Human liver plasma membranes contain receptors for the hepatitis B virus pre-S1 region and, via polymerized human serum albumin, for the pre-S2 region. J Virol 63: 1981-1988. 
Citation: Ueda K, Omori H (2015) Successful Generation of Hepatitis B virus (HBV) Pseudotype Particle; A Versatile Tool for Identification of the HBV Receptor and Investigation of HBV Infectivity. J Liver 4: 169. doi:10.4172/2167-0889.1000169

Page 7 of 7

40. Hertogs K, Leenders WP, Depla E, De Bruin WC, Meheus L, et al. (1993) Endonexin II, present on human liver plasma membranes, is a specific binding protein of small hepatitis B virus (HBV) envelope protein. Virology 197: 549-557.

41. Treichel U, Meyer zum Büschenfelde KH, Stockert RJ, Poralla T, Gerken $\mathrm{G}$ (1994) The asialoglycoprotein receptor mediates hepatic binding and uptake of natural hepatitis $\mathrm{B}$ virus particles derived from viraemic carriers. J Gen Virol 75 : 3021-3029.

42. Zhang X, Lin SM, Chen TY, Liu M, Ye F, et al. (2011) Asialoglycoprotein receptor interacts with the preS1 domain of hepatitis $B$ virus in vivo and in vitro. Arch Virol 156: 637-645.

43. Deng Q, Zhai JW, Michel ML, Zhang J, Qin J, et al. (2007) Identification and characterization of peptides that interact with hepatitis $B$ virus via the putative receptor binding site. J Virol 81: 4244-4254.

44. Urban S, Breiner KM, Fehler F, Klingmüller U, Schaller H (1998) Avian hepatitis B virus infection is initiated by the interaction of a distinct pre-S subdomain with the cellular receptor gp180. J Virol 72: 8089-8097.

45. Yan H, Zhong G, Xu G, He W, Jing Z, et al. (2012) Sodium taurocholate cotransporting polypeptide is a functional receptor for human hepatitis $\mathrm{B}$ and D virus. elife 1: e00049.

46. Ueda K (2013) Start or end ? One of the Biggest mysteries is finally solved? J Infect Dis Ther 1: e101.

47. Ueda K (2013) One year passed since a bile acid transporter (sodium taurocholate cotransporting peptide [NTCP]) was nominated as a hepatitis B virus (HBV) entry receptor; has the NTCP been as a ral HBV receptor? J. Infect Dis Ther $1:$ e102.
48. Neurath AR, Kent SB, Strick N, Parker K (1986) Identification and chemical synthesis of a host cell receptor binding site on hepatitis $\mathrm{B}$ virus. Cell 46: 429-436.

49. Pontisso P, Ruvoletto MG, Gerlich WH, Heermann KH, Bardini R, et al. (1989) Identification of an attachment site for human liver plasma membranes on hepatitis B virus particles. Virology 173: 522-530.

50. Glebe D, Urban S, Knoop EV, Cag N, Krass P, et al. (2005) Mapping of the hepatitis B virus attachment site by use of infection-inhibiting preS1 lipopeptides and tupaia hepatocytes. Gastroenterology 129: 234-245.

51. Bremer CM, Sominskaya I, Skrastina D, Pumpens P, El Wahed AA, et al. (2011) N-terminal myristoylation-dependent masking of neutralizing epitopes in the preS1 attachment site of hepatitis B virus. J Hepatol 55: 29-37.

52. Engelke M, Mills K, Seitz S, Simon P, Gripon P, et al. (2006) Characterization of a hepatitis $\mathrm{B}$ and hepatitis delta virus receptor binding site. Hepatology 43: 750-760.

53. Blanchet M, Sureau C (2006) Analysis of the cytosolic domains of the hepatitis $\mathrm{B}$ virus envelope proteins for their function in viral particle assembly and infectivity. J Virol 80: 11935-11945.

54. Abou-Jaoudé G, Sureau C (2007) Entry of hepatitis delta virus requires the conserved cysteine residues of the hepatitis $\mathrm{B}$ virus envelope protein antigenic loop and is blocked by inhibitors of thiol-disulfide exchange. J Virol 81: 13057-13066. 